\title{
Minimally Invasive Pedicle Screw Fixation, Including the Fractured Vertebra, Combined with Percutaneous Vertebroplasty for Treatment of Acute Thoracolumbar Osteoporotic Compression Fracture in Middle-Age and Elderly Individuals
}

hong liu

Orthopedic Institute

jinwei Xu

Orthopedic Institute

guanrong Sun

Orthopedic Institute

weifeng Shi

Orthopedic Institute

liming Xiang

Orthopaedic Hospital

shan Chen ( $\nabla$ chenshanzj@163.com )

HangZhou Hospital of Traditional Chinese Medical

Research article

Keywords: Thoracolumbar vertebroplasty, Pedicle screw fixation, osteoporotic

Posted Date: August 9th, 2021

DOI: https://doi.org/10.21203/rs.3.rs-750840/v1

License: (c) (i) This work is licensed under a Creative Commons Attribution 4.0 International License.

Read Full License 


\section{Abstract}

Background: To evaluate the feasibility, efficacy, and safety of minimally invasive pedicle screw (MIPS) fixation, including the fractured vertebra, combined with percutaneous vertebroplasty (PVP) for the treatment of acute thoracolumbar osteoporotic compression fracture in middle-age and elderly individuals.

Methods: Between January 2016 and August 2019, a total of 30 patients, with a mean age of 69.4 years (range, 58-75 years), who experienced thoracic or lumbar fracture without neurological deficits, underwent the MIPS procedure combined with PVP. Preoperative and postoperative pain were assessed using a visual analog scale (VAS) and Oswestry Disability Index (ODI). Cobb angles and anterior column height were measured on lateral radiographs before surgery and at 3 days, 1, 3, and 6 months, and 1 and 2 years at final follow-up after surgery.

Results: All patients underwent surgery successfully, with a mean follow-up of $18.2 \pm 5.7$ months (range, 12-45 months). Mean preoperative VAS score decreased from $7.3 \pm 2.2$ to $1.4 \pm 0.3$ at the final follow-up $(p<0.05)$. Mean preoperative ODI decreased from $84.2 \pm 10.3$ to $18.8 \pm 7.5(p<0.05)$ at the final follow-up. The Kyphosis angle of operative segment was improved from preoperative $(21.38 \pm 1.68)^{\circ}$ to $(4.01 \pm 1.38)^{\circ} 3$ days postoperatively and $(5.02 \pm 1.09)^{\circ}$ at final follow up $(p<0.05)$. The anterior vertebral height was improved from preoperative $(49.86 \pm 6.50) \%$ to(94.01 \pm 1.79$) \% 3$ days postoperatively and $(91.80 \pm 1.88) \%$ at final follow up $(p<0.05)$. No significant changes in vertebral body height restoration were observed during 2 years of follow-up after surgery. In addition, there were no instrumentation failures or complications in any of the patients.

Conclusions: MIPS, including the fractured vertebra, combined with PVP, was a reliable and safe procedure, with satisfactory clinical and radiological results for the treatment of thoracolumbar osteoporotic compression fracture in patients without neurological deficits.

\section{Introduction}

The incidence of osteoporotic vertebral fractures (OVCF) has increased rapidly in recent years due to the aging population. Surgical intervention for OVCF has been widely accepted as an effective treatment method because it has several advantages, including immediate spinal stability and more reliable restoration of sagittal alignment, vertebral height, and canal dimension[1]. Some studies have described a technique involving 4-screw fixation immediately adjacent to the fractured vertebra combined with cement augmentation. Clinical and biomechanical studies have confirmed that addition of pedicle screw fixation in fractured vertebrae significantly improved stability compared with conventional 4-screw fixation for thoracolumbar fractures[2, 3]. Minimally invasive surgery has been successfully used in the treatment of vertebral fractures, and more studies have reported that the technique is associated with less soft tissue destruction, reduced intraoperative blood loss, and shorter hospitalization[4]. In the present study, we designed a minimally invasive pedicle screw (MIPS) fixation technique, including the fractured 
vertebra, combined with percutaneous vertebroplasty (PVP) to treat patients with thoracolumbar osteoporosis vertebral compressive fractures, which could prevent secondary fractures after PVP [5]. The purpose of this study was to evaluate the feasibility, efficacy, and safety of MIPS fixation, including the fractured vertebra, combined with PVP.

\section{Methods}

\section{Surgical Procedure}

After general tracheal anesthesia, the fractured and adjacent vertebral pedicles are identified under C-arm fluoroscopy of 6 pedicle projections, and an intact pedicle of the injured vertebra is fitted with screws (preoperative computed tomography scan), and the entry site to the pedicle is located at the junction between the lateral border of the superior articular facet and the bisecting midline of the transverse process. Once the pedicle is identified, a pedicle probe is used to enter the pedicle, and preoperative anteroposterior and lateral roentgenograms and computed tomography (CT) scans through the pedicles of the vertebral body to be instrumented are assessed to determine the optimal angle of entry in both the coronal and sagittal planes. Pedicle integrity is verified in all five quadrants to ensure the presence of a solid tube of bone and that violation of the spinal canal or inferiorly into the neuroforamen has not occurred. The tip of the needle is positioned at the 10 and 2 points of the left and right pedicle. The puncture angle (anteroposterior, introversion angle $10^{\circ}-15^{\circ}$ ) is determined and five hollow pedicle screws are torqued in. C-arm fluoroscopy is activated again and the tip of the screw is positioned in the front onequarter to one-third of the vertebral body to confirm that the position is satisfactory. One side of the three screws is fixed first, and then the screws are torqued in and the nuts are tightened. The order of fixation is injured vertebra, lower vertebrae, and upper vertebrae. According to the degree of compression of the injured vertebra before the operation, the reduction should be performed between the injured vertebra and the upper vertebra. Fluoroscopy is used to confirm that the working channel enters the front one-third of the injured vertebra. A bone cement injection tube with an inner core is inserted. After mixing the bone cement to the dough stage, it is injected under fluoroscopic guidance. When the bone cement flows backward and approaches the posterior edge of the vertebral body, the injection is immediately stopped. The side connecting rod is fixed and C-arm fluoroscopy is activated to confirm satisfactory positioning of the implant, and the skin is sutured.

\section{Postoperative management}

Antibiotics were routinely administered to prevent infection, with standing or walking under the protection of a thoracolumbar brace for 2 weeks after the operation, with the lumbar brace removed 1.5 months after the operation.

\section{Clinical assessment}


The following clinical indexes were observed and recorded: operation duration; surgical blood loss; amount of cement instillation; and number of cement leakages. A visual analog scale (VAS) was used to evaluate back pain. VAS pain assessments were performed immediately, preoperatively, at 3,14 days, at 1, $3,6,12$ months and the final follow-up after surgery. The Oswestry disability index (ODI) was used to evaluate functional outcome, the plain radiographs were captured preoperatively, immediately postoperatively, and at the final follow-up. The following parameters were observed and analyzed: local kyphotic angle, defined as the angle measured between the superior endplate of the upper vertebra and the inferior endplate of the lower vertebra; and percentage of anterior height of the fractured vertebra. The anterior height of the fractured vertebra was defined as the anterior height of the fractured vertebra divided by the normal anterior height of the vertebra. Cobb angles and anterior vertebral body height were measured on lateral radiographs. The fractured and restored heights were calculated as a percentage of the estimated intact vertebral body height by averaging the anterior height from the adjacent levels.

\section{Statistical analysis}

Data are expressed as mean \pm standard deviation (SD) and were analyzed using SPSS version 22.0 (IBM Corporation, Armonk, NY, USA). The paired Student's $t$-test and Dunnett's $t$ test were used to evaluate changes in data at different times, and the VAS score, Cobb angle in the sagittal plane, and anterior height ratio of injured vertebrae were assessed using X-ray. The anterior vertebral height ratio and sagittal Cobb angle at different time were compared using repeated measures analysis of variance. Pairwise comparisons at different times after the operation were performed using Dunnett's $t$ test; differences with $p<0.05$ were considered to be statistically significant.

\section{Results}

Thirty patients (10 male, 20 female) who experienced thoracolumbar fracture(s) without neurological symptoms were treated using the surgical method described above. Lesions were identified at the following anatomical locations: T11 $(n=2) ; T 12(n=8) ; L 1(n=12) ; L 2(n=5)$; and L3 $(n=3)$. The fractures were classified as type A1.1 $(n=6[20 \%]), A 1.2(n=5[16.7 \%])$, and A1.3 $(n=19[63.3 \%])$. All patients underwent surgery successfully as planned, with a mean follow-up of $18.2 \pm 5.7$ months (range, $12-45$ months). The mean duration of surgery was $83.2 \pm 23.5 \mathrm{~min}$ (range, $72-108 \mathrm{~min}$ ), with a mean blood loss of $98.5 \pm 18.6 \mathrm{ml}$ (range, $65-120 \mathrm{ml}$ ), and a mean instillation of cement of $2.1 \pm 0.7 \mathrm{ml}$ (range, $1.5-3 \mathrm{ml})$. Cement leakage was observed in $5(16.3 \%)$ cases, 3 at the adjacent discal space and 2 at the anterior of the fractured vertebra, none of which had clinical consequences. There was no infection and no neurological complications. No screw pullouts were found at the final follow-up. The mean preoperative back pain score according to VAS decreased from $7.3 \pm 2.2$ to $2.2 \pm 1.1$ at discharge $(p<$ $0.05)$, and was $1.4 \pm 0.3$ at the final follow-up $(p<0.05)$. The mean ODI preoperative decreased from 84.2 \pm 10.3 to $18.8 \pm 7.5$ at the final follow-up $(p<0.05)$. The Kyphosis angle and anterior vertebral height preoperatively, postoperatively, and at the final follow-up period are reported in Table 1 . The Kyphosis angle of operative segment was improved from preoperative $(21.38 \pm 1.68)^{\circ}$ to $(4.01 \pm 1.38)^{\circ} 3$ days 
postoperatively and $(5.02 \pm 1.09)^{\circ}$ at final follow up $(p<0.05)$. The anterior vertebral height was improved from preoperative $(49.86 \pm 6.50) \%$ to $(94.01 \pm 1.79) \% 3$ days postoperatively and $(91.80 \pm 1.88) \%$ at final follow up $(p<0.05)$.

\section{Table 1}

Variations of each measured parameter preoperatively, postoperatively and at latest follow-up (measured as mean $\pm \mathrm{SD}$ ).

\begin{tabular}{|c|c|c|c|c|c|}
\hline Time & $\begin{array}{l}\text { Kyphosis angle } \\
\left({ }^{\circ}\right)\end{array}$ & $\begin{array}{l}\text { Anterior height } \\
(\%)\end{array}$ & VAS & ODI & \\
\hline Preop & $21.38 \pm 1.68$ & $49.86 \pm 6.50$ & $7.3 \pm 2.2$ & $\begin{array}{l}84.2 \pm 10.3 \\
\pm 10.3\end{array}$ & $84.2 \pm 10.384 .2$ \\
\hline 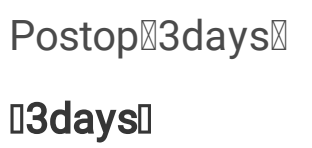 & $4.01 \pm 1.38$ & $94.01 \pm 1.79$ & $2.7 \pm 1.7$ & $27.7 \pm 11.5$ & \\
\hline $\begin{array}{l}\text { Postop(1 } \\
\text { months) }\end{array}$ & $4.67 \pm 1.50$ & $93.16 \pm 1.83$ & $2.3 \pm 1.5$ & $25.2 \pm 9.5$ & \\
\hline $\begin{array}{l}\text { Postop(3 } \\
\text { months) }\end{array}$ & $4.93 \pm 1.43$ & $92.94 \pm 1.84$ & $2.2 \pm 0.5$ & $23.1 \pm 8.9$ & \\
\hline $\begin{array}{l}\text { Postop(6 } \\
\text { months) }\end{array}$ & $4.97 \pm 1.42$ & $92.83 \pm 1.82$ & $1.5 \pm 0.6$ & $21.5 \pm 7.8$ & \\
\hline $\begin{array}{l}\text { Postop(12 } \\
\text { months) }\end{array}$ & $4.99 \pm 1.31$ & $92.53 \pm 1.78$ & $1.4 \pm 0.5$ & $19.2 \pm 8.2$ & \\
\hline final follow-up & $5.02 \pm 1.09$ & $91.80 \pm 1.88$ & $\begin{array}{l}1.4 \pm \\
0.3\end{array}$ & $18.8 \pm 7.5$ & \\
\hline $\begin{array}{l}\text { Note } \ \text { Compariso } \\
\text { and last follow-u } \\
\text { days after opera }\end{array}$ & $\begin{array}{l}f \text { the anterior vert } \\
=1169.135 P<0.0 \\
\text { and last follow-u }\end{array}$ & $\begin{array}{l}\text { ral body height } \\
\text { Comparison of } \\
F=403.697 P<\end{array}$ & $\begin{array}{l}\text { ong preop } \\
\text { sagittal C }\end{array}$ & $\begin{array}{l}\text { ation } 3 \text { days } \\
\text { ob angle am }\end{array}$ & $\begin{array}{l}\text { fter operation } \\
\text { g preoperation } 3\end{array}$ \\
\hline
\end{tabular}

\section{Discussion}

Surgical treatment can restore vertebral body height, correct angular deformity, decompress neural tissue, and facilitate rapid mobilization and rehabilitation.Percutaneous pedicle screw internal fixation has been successfully used in the treatment of OVCF and compared with standard open approaches is associated with less soft tissue destruction (muscle atrophy and denervation), reduced intraoperative blood loss, and shorter hospitalization. The integrity of the posterior spinal complex preserved[4]. In the past, surgical procedures included the midline and multifidus approach, which resulted in pain and complications associated with spinal degeneration. Short-segment pedicle screw internal fixation for thoracolumbar fractures has been widely used in clinical practice. Posterior fixation of the injured vertebra in the short segment of the 4 screws should be used most extensively [6]; however, some studies have confirmed 
many problems with this method[7]. The reasons are as follows: the injured vertebra forms a so-called "eggshell." The short segment fixation combined with injured vertebral screw placement can be used to effectively treat OVCF in aging patients[8], following the principle of three-point fixation which can better correct the kyphosis of fractures and maintain reduction[9]. The safety and advantages of injured vertebral screws in reduction and maintenance of reduction have been recognized. However, a currently encountered problem is whether unilateral vertebral screw placement combined with a short segment pedicle screw can achieve satisfactory reduction and maintain good reduction. Some authors have compared the biomechanical stability effects of 4,5 , and 6 pedicle screw fixation in the treatment of thoracolumbar fractures using fresh spine cadaver specimens[10]. The results demonstrated that 5 or 6 screws could improve the biomechanical stability of the vertebrae, and the stability effect was better than that of the traditional 4 screws. There was no significant difference in stability between 5 and 6 screws.

In the present study, percutaneous short-segment pedicle screw fixation, including the fractured vertebra, combined with PVP was performed in middle-age and elderly individuals, and the results demonstrated that a good curative effect could be obtained[11].The improvement was significant 3 days after surgery and ODI compared with that before surgery, and there was no statistically significant difference between Cobb angles at the last follow-up and 2 weeks after surgery. Moreover, the Cobb and wedge angles could effectively maintain postoperative VAS scores and ODI, which were significantly decreased compared with preoperative values. No serious complications occurred, indicating that this technique can effectively restore and maintain spinal sequence, assist in relieving pain and improve clinical function. In percutaneous posterior short segment pedicle fixation combined with PVP, short-segment pedicle fixation was used to alter spinal force conduction and obtain a strong fixed and stable central column, which enhances the stability of the anterior column to prevent mechanical access. Meanwhile, local release of high temperature through bone cement prevents rapid pain relief from chemical access, improving the local biomechanical stability of the fracture area and the anterior central column. Unilateral PVP of the injured vertebra was used to avoid the loss of the anterior column again, and the pain were blocked by strengthening stability and local heat release[12].

There are some limitations concerning our study. It is a retrospective study, the number of patients is limited, the follow-up time is short, and there is a lack of control group comparing other possible surgical approaches, Randomized controlled trials should be conducted to verify its safety and efficacy in future studies.

\section{Declarations}

\section{Ethics approval and consent to participate}

This study was conducted in accordance with the Declaration of Helsinki. This study was conducted with approval from the Ethics Committee of Xiaoshan District Hospital of TCM and Hangzhou Hospital of TCM. Written informed consent was obtained from all participants. 


\section{Consent for Publication}

Written informed consent was obtained from all participants.

\section{Availability of data and material}

This data will not be shared, because in recent years, although many scholars have explored this in various aspects, its pathological mechanism remains unclear and there are no standard diagnostic criteria. In order to determine the effective method for preventing and treating this disease, it is necessary to proceed with more large-scale and clinical studies.

\section{Competing interests}

The authors declare that they have no competing interests. There is no funding source.

\section{Funding}

There is no funding source.

\section{Authors' contributions}

LH was accountable for the integrity and analysis of the data, and the writing of the manuscript. XJW and SGR were accountable for the integrity and analysis of the data. SWF and XLM were accountable for the analysis of the data. CS was accountable for the conception of the research. All authors read and approved the final manuscript.

\section{Acknowledgements}

The authors would like to thank all participating patients, as well as the study nurses, co-investigators, and colleagues who made this trial possible.

\section{References}

1. Scheer JK, Bakhsheshian J, Fakurnejad S, Oh T, Dahdaleh NS. Z.A. Smith.Evidence-Based Medicine of Traumatic Thoracolumbar Burst Fractures: A Systematic Review of Operative Management across 20 Years Global Spine J.5 (1) (2015), pp. 73-82.

2. Sun C, Guan G, Liu X, Zhang H, Wang B. Comparison of short-segment pedicle fixation with versus without inclusion of the fracture level in the treatment of mild thoracolumbar burst fractures. Int $\mathrm{J}$ Surg. 2016;36:352-7. 
3. Norton RP, Milne EL, Kaimrajh DN, Eismont FJ, Latta LL, Williams SK. Biomechanical analysis of fourversus six-screw constructs for short-segment pedicle screw and rod instrumentation of unstable thoracolumbar fractures. Spine J. 2014;14(8):1734-9.

4. Schnake KJ, Schroeder GD, Vaccaro AR, Oner C. AOSpine classification systems (subaxial, thoracolumbar). J Orthop Trauma. 2017;31(Suppl 4):14-23.

5. Wang B, Zhao CP, Song LX, Zhu L. Balloon kyphoplasty versus percutaneous vertebroplasty for osteoporotic vertebral compression fracture: a meta-analysis and systematic review. J Orthop Surg Res. 2018;22(1):264.

6. Kanna RM, Shetty AP, Rajasekaran S. Posterior fixation including the fractured vertebra for severe unstable thoracolumbar fractures. Spine J. 2015;15(2):256 - 64ãष区.

7. Krüger A, Zettl R, Ziring E, Mann D, Schnabel M, Ruchholtz S. Kyphoplasty for the treatment of incomplete osteoporotic burst fractures. Eur Spine J. 2010;19(6):893-900.

8. Han L Quan, RenFu, et al. Efficacy comparison of percutaneous pedicle instrumentation combined with vertebral fracture fixation or vertebral augmentation for treatment of osteoporotic thoracolumbar fractures in elderly patients. Chin J TraumaMarch. 2017;33(3):213-8.

9. Zeng ZL,Cheng LM,Qian L,et a1.Unilateral pedicle screw fixation through the pedicle of fractured vertebra in combination with the short segment of pedicle screw in the treatment of thoracolumbar fracture of mild to moderate instability[J].Chinese journal of surgery.2012,50(3). -237 .

10. Norton RP, Milne EL, Kaimrajh DN, Eismont FJ, Latta LL, Williams SK. Biomechanical analysis of fourversus six-screw constructs for short-segment pedicle screw and rod instrumentation of unstable thoracolumbar fractures. Spine J. 2014;14(8):1734-9.

11. Huang YS, Ge CY, Feng H,et al.Bone cement-augmented short-sement pedicle for kummell disease with Spinal Canal stenosis[J].Med SciMonit2018,14(24):928-935.

12. Long 12 ChengX, Xu HQ, Huang JH, Li YL. FB. Comparison of unilateral versus bilateral percutaneous kyphoplasty for the treatment of patients with osteoporosis vertebral compression fracture (OVCF): a systematic review and meta-analysis. Eur Spine J. 2016;25(11):3439-49.

\section{Figures}




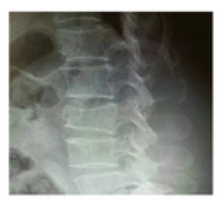

A

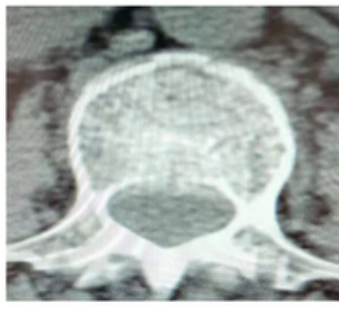

B1

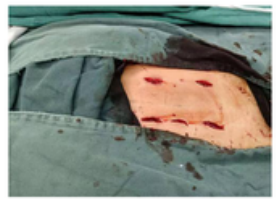

D

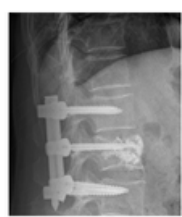

$\mathbf{E}$

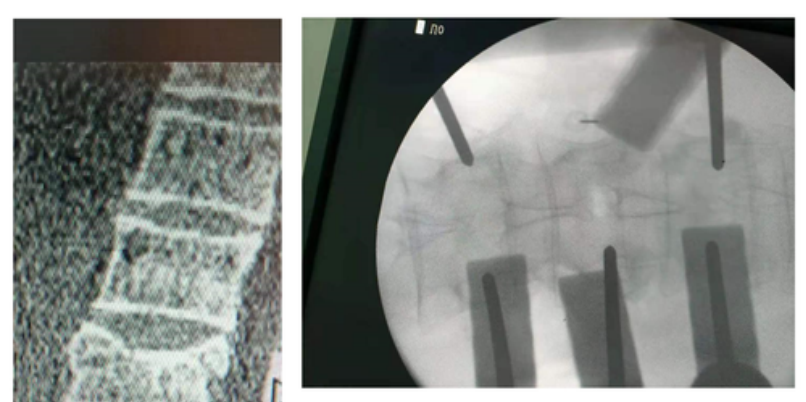

C1

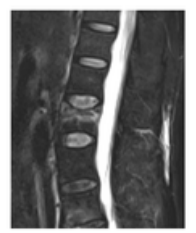

$\mathbf{F}$

B2

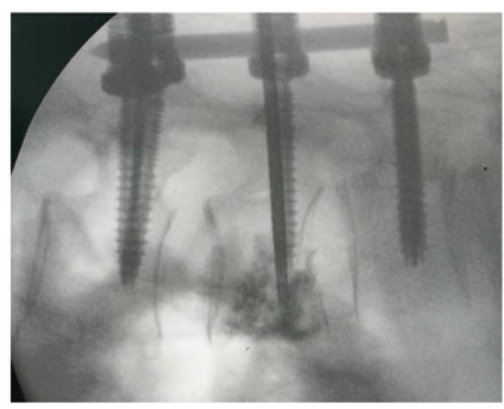

C2

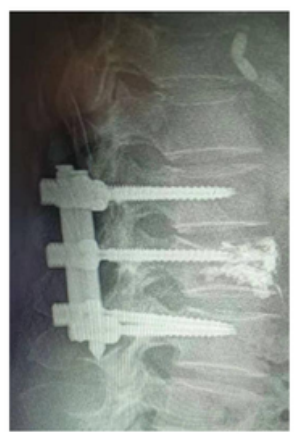

H

\section{Figure 1}

A 70-year-old Female patient with L2 osteoporotic compression fracture underwent MIPS combined with

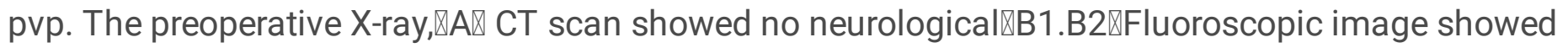
placement of pedicle screws (C1),the injection of bone cement. the placement of rods (C2)Using a invasive technique(D), lateral X-ray immediately after surgery $(E)$ and $M R I$ showed $L 2$ fresh fracture $(F)$, the Cobb angle was $21.2^{\circ}$,E Postoperative X-ray showed the fractured vertebral was restored, the correction of local kyphotic angle was $19.3^{\circ}$, and the anterior vertebral height was almost normal. $\mathrm{H}$ The final follow-up X-ray showed the correction was greatly maintained, the kyphosis was only $2.6^{\circ}$, and the anterior vertebral height was $92 \%$. 